\title{
Study of choices of contraception in postpartum women in a tertiary care institute in Mumbai, Maharashtra, India
}

\author{
Aliya Farogh*, Tushar Palve \\ Department of Obstetrics and Gynecology, Grant Government College and Sir JJ Group of Hospital, Mumbai, \\ Maharashtra, India \\ Received: 12 November 2019 \\ Accepted: 05 December 2019 \\ *Correspondence: \\ Dr. Aliya Farogh, \\ E-mail: aliyafarogh@gmail.com \\ Copyright: (c) the author(s), publisher and licensee Medip Academy. This is an open-access article distributed under \\ the terms of the Creative Commons Attribution Non-Commercial License, which permits unrestricted non-commercial \\ use, distribution, and reproduction in any medium, provided the original work is properly cited.
}

\begin{abstract}
Background: This modern era talks about women strength and empowerment where they are working either equally or one step ahead of men. However, a fall back in making decisions for contraception use and family planning can still be observed. It is most frequently seen among women belonging to some village as they are exposed to a minimal health care. Keeping this in mind, this crucial period was considered as opportunity to test the issue regarding the various choices of contraception available. Objective of this study was to find out the criteria and methods of contraception selected by women in the postpartum period.

Methods: A cross-sectional study in the department of obstetrics and gynaecology was conducted over a period of $11 / 2$ years in which a total of 150 postpartum women were interrogated and counselled regarding various methods of contraception.

Results: The contraceptive methods most commonly selected in postpartum period are PPIUCD, Barrier, tubal ligation and injectable contraception of which condom is the most common method adopted. The important factors responsible for the choice of contraception include parity, breast- feeding, education and socio-economic status of the women.

Conclusions: Postpartum period is particularly important for initiating contraception as the largest proportion with unmet need of contraception is found among those in their first year after child birth. In order to space birth in a healthy manner postpartum contraception should be emphasized upon.
\end{abstract}

Keywords: Contraception, Contraceptive choice, Methods of contraception, Postpartum women

\section{INTRODUCTION}

Post-partum period is an ideal time to initiate contraception as it is critical for maternal and child health due to various reasons. Women who are already accessing the health care system and are known to not be pregnant have increased motivation to avoid pregnancy, thus, are more likely motivated to initiate contraception. The postpartum period is an important time to initiate contraception because women are accessing the healthcare system and might have increased motivation to avoid another pregnancy, writes Naomi K. Tepper, MD, from the division of reproductive health, national centre for chronic disease prevention and health promotion, CDC, and colleagues. ${ }^{1}$ The studies have shown that with family planning, and spaced pregnancy, maternal and child mortality rates can be reduced to a greater extent. In the year 1951, India was the first to come up with a family planning programme.

Post- partum period is very crucial for women especially those belonging to the rural community as this may be the 
only time, they come in contact with the health personnel and is in a mood to listen to health advices. Because contraception has to be initiated soon after the delivery of the women, discussion of the patients' needs and preferences should begin early; ideally in third trimester. According to 2 subject of postpartum contraception is much better raised during the third trimester, at around 30 weeks' gestation, and discussed again with the woman during the postpartum visit at around 10 days. $^{2}$ The choice of a post-partum contraceptive method depends on many factors, including the need for a temporary versus a permanent method, and the infant feeding choice. ${ }^{3}$ For exclusive breast-feeding women, contraception should be started at least by the end of third post- partum month, whereas for non-breastfeeding women contraception should begin in the third post- partum week. Combined oestrogen/progestin methods should be avoided by all women for 2-3 weeks to avoid elevating the risk of thromboembolism. Preparations containing oestrogen should be avoided altogether during lactation because they have been associated with a reduction in milk production. POPs, implants and injectables are appropriate regardless of infant feeding choice. It is best to insert IUDs within 10 minutes of delivery of the placenta, in order to minimize the risk of IUD expulsion. Tubal sterilization is safe, convenient and cost-effective when performed immediately after delivery, but it requires extensive counselling and fully informed consent. LAM is a method that can only be used by breast-feeding women.

An increase in contraception use during the post- partum period significantly reduces maternal and infant mortality rates by preventing unplanned and unwanted pregnancy and spacing new pregnancies to at least two years after the previous birth. ${ }^{4}$ Hence, post-partum period is particularly important for initiating contraception to space births in a healthy manner.

The present study was carried out in light of above facts with the aim to study the types of contraception most commonly accepted by women in postpartum period in Mumbai.

\section{METHODS}

The present study was conducted to study the type of contraception preferred by women in post- partum period depending upon breast- feeding, number of children, and desire for further child bearing. The prospective study was carried out on 150 women over a period of one and half year in the post- partum period randomly selected in the department of obstetrics and gynaecology in a tertiary care institute. All of the women included in the study preferred exclusive breast feeding which influenced their choice of contraception.

The women were interrogated on a pre-tested prestructured questionnaire. The domains of questionnaire included demographic data like age, education and occupation of both the partners, parity etc., data on awareness about the various methods of contraception, their source of information. Detailed clinical history was taken and general and gynecological examinations were done. Informed consent was taken from all women. An assessment with respect to the degree of knowledge that the women have regarding the awareness of contraception and its various methods was been made. The women considered to be knowledgeable have information of at least one method of contraception with its usage. Women who have recently delivered were a part of this study only after informed consent. They were counselled about various contraception methods available and allowed to choose a method of their choice for contraception. Other factors such as number of children at present and child bearing needs in the future, religious beliefs and customs were also considered in making the decision.

\section{Inclusion criteria}

- Women delivered in the tertiary care centre between December 2017 and June 2019 who were willing for contraception

- Patients willing to participate in the study.

\section{Exclusion criteria}

- Women with medical disorders

- Women not willing for contraception

- Women not giving consent for study.

\section{Statistical analysis}

The software used in this study for statistical analysis is SPSS (Statistical Package for Social Sciences) version.

\section{RESULTS}

Among all the participants, 42 out of 150 women (28\%) opted for PPIUCD, 45 women $(30 \%)$ chose Barrier method, 42 out of 150 (28\%) selected Permanent sterilization, and 21 women $(14 \%)$ decided on Injectable contraception (Table 1).

Table 1: Common methods of contraception.

\begin{tabular}{|lll|}
\hline Method of contraception & Number & $\%$ \\
\hline PPIUCD & 42 & $28 \%$ \\
\hline Barrier & 45 & $30 \%$ \\
\hline Permanent sterilization & 42 & $28 \%$ \\
\hline Injectable contraception & 21 & $14 \%$ \\
\hline
\end{tabular}

Table 2 shows the socio-demographic profile of study participants. The maximum women $(53.33 \%)$ belonged to the age group 25-31 years. $28 \%$ women were in the age group 18-24 years followed by $17.33 \%$ in $32-39$ years of age. Only $1.33 \%$ women were above 40 years of age. 
Table 2: Demographic characteristics.

\begin{tabular}{|c|c|c|c|}
\hline Characteristics & & Number & $\%$ \\
\hline \multirow{4}{*}{ Age in years } & $18-24$ & 42 & $28 \%$ \\
\hline & $25-31$ & 80 & $53.33 \%$ \\
\hline & $32-39$ & 26 & $17.33 \%$ \\
\hline & $40+$ & 2 & $1.33 \%$ \\
\hline \multirow[b]{2}{*}{ Parity } & One child & 37 & $24.66 \%$ \\
\hline & $\begin{array}{l}\text { More than } \\
\text { one child }\end{array}$ & 113 & $75.33 \%$ \\
\hline \multirow{4}{*}{ Education } & Illiterate & 21 & $14 \%$ \\
\hline & Primary & 55 & $36.66 \%$ \\
\hline & Secondary & 29 & $19.33 \%$ \\
\hline & $\geq \mathrm{SSC}$ & 45 & $30 \%$ \\
\hline
\end{tabular}

Statistical analysis was done using Pearson Chi square test and P-value is 0.002 which is statistically significant.

All of the women (100\%) intended to exclusively breastfeed their children during the first six months of delivery and hence, needed a method of contraception which would not interfere with lactation.
There were $24.66 \%$ women with single child whereas $75.33 \%$ of women had more than one child. P-value is 0.0001 which is statistically significant, proving that number of children has a significant effect on decision regarding contraception and its type.

Approximately $86 \%$ were literate out of which $33.66 \%$ up to primary school, and $19.33 \%$ up to high school, only $30 \%$ up to post high school diploma and post graduate. Pvalue is 0.142 which is statistically non-significant.

The type of contraception selected by women depended upon many factors of which number of children was of the top most priority. Women with single child opted for spacing methods such as condoms and injectable contraception whereas permanent method such as Tubal ligation was selected only after completion of family.

Among the women with single child, barrier method was the most common method of contraception (59.45\%) followed by DMPA injection which accounted for $29.7 \%$. Only 4 out of 37 women with single child selected PPIUCD (10.8\%) and permanent method was not chosen by any of these women.

Table 3: Type of contraception based on parity.

\begin{tabular}{|lllll|l|}
\hline Parity & Total & PPIUCD & Barrier & TL & DMPA \\
\hline One child & 37 & $4(10.8 \%)$ & $22(59.45 \%)$ & - & $11(29.7 \%)$ \\
\hline More than one child & 113 & $38(33.6 \%)$ & $23(20.35 \%)$ & $42(37.16 \%)$ & $10(8.8 \%)$ \\
\hline
\end{tabular}

Out of 113 women with more than one child maximum women $(37.16 \%)$ opted for tubal sterilisation. The second most common method of contraception in these women was PPIUCD (33.6\%). Barrier was selected by 23 out of 113 women $(20.35 \%)$ and the least common method was Injectable contraception (8.8\%) (Table 3).

\section{DISCUSSION}

In this study, maximum acceptance (53.33\%) of contraception seen in 25-31 years of age which is similar to studies conducted by Shrivastav $\mathrm{R}$ et al in Gorakhpur and Monahan $\mathrm{P}$ et al. ${ }^{5,6}$

Shrivastav R et al concluded in their study "contraceptive knowledge attitude and practice (KAP) survey" that the most commonly used contraceptive was condom (34.5\%), which is also seen in this study.

In present study, the educational status of the women and number of children were significant predictors of the type of contraception chosen by them. Association of higher education status with knowledge of spacing contraception has been observed by other Hayat et al and Patro BK et al in their studies.

Among the women with single child the most common method of contraception is Barrier method (59.45\%) followed by DMPA. Permanent sterilization (TL) is the most common method in women with completed family $(60.6 \%)$. This was also seen in study by Thulaseedharan et al. ${ }^{9}$

Such significant studies have also been conducted by other Indian authors illustrating correlation between contraceptive practice and education, parity, and socioeconomic status with similar findings. 3,10

\section{CONCLUSION}

The most common method of contraception in this study is Barrier method (condom).

Our study reveals that breastfeeding pattern, occupation, parity, preferred number of children, time since delivery, mode of delivery, education level, and socioeconomic status are the major limiting factors in accepting family planning methods. There is a need for proper promotion 
of spacing methods by government and ground level workers and motivation of couples to accept them.

The present study recommends providing family planning services in antenatal counselling specially in presence of husband for making decision of contraception in postpartum period and implementing it in immediate postpartum period before discharge of women from the hospital so as ensure the contraceptive acceptance and its use among them.

Funding: No funding sources Conflict of interest: None declared

Ethical approval: The study was approved by the Institutional Ethics Committee

\section{REFERENCES}

1. Gavin L, Moskosky S, Carter M, Curtis K, Glass E, Godfrey E, et al. Providing quality family planning services: recommendations of CDC and the US office of population affairs. Morbidity and mortality weekly report. Recommen Reports. 2014;63(4):1-54.

2. Guillebaud J. Postpartum contraception. unnecessary before three weeks. BMJ: $\mathrm{Br}$ Med J. 1993;307(6918):1560.

3. Kennedy KI. 2 Post-partum contraception. Baillière's clinical obstetrics and gynaecology. 1996;10(1):25-41.

4. Gaikwad RA, Gadappa SN, Deshpande SS. Awareness of contraception in post-partum women in a tertiary care centre. Int J Repro Contracep Obstet Gynecol. 2017;6(9):3851.
5. Srivastava R, Srivastava DK, Jina R, Srivastava K, Sharma N, Saha S. Contraceptive knowledge, attitude and practice (kap survey). J Obstet Gynecol India. 2005;55(6):546-50.

6. Mohanan P, Kamath A, Sajjan BS, et al. Fertility pattern and family planning practices in a rural area in Dakshina Kannada. Indian $\mathbf{J}$ Comm Med. 2003;28(1): 15 .

7. Hayat H, Khan PS, Imtiyaz B, Hayat G, Hayat R. Knowledge, attitude and practice of contraception in rural Kashmir. J Obstet Gynecol India. 2013;63(6):410-4.

8. Patro BK, Kant S, Baridalyne N, Goswami AK. Contraceptive practice among married women in a resettlement colony of Delhi. Health Popul Perspect Issues. 2005;28(1):9-16.

9. Thulaseedharan JV. Contraceptive use and preferences of young married women in Kerala, India. Open Access J Contracept. 2018;9:1.

10. Ehsanpour S, Mohammadifard M, Shahidi S, Nekouyi NS. A comparative study on attitude of contraceptive methods users towards common contraceptive methods. Iranian J Nurs Midwifery Res. 2010;15(Supp11):363.

Cite this article as: Farogh A, Palve T. Study of choices of contraception in postpartum women in a tertiary care institute in Mumbai, Maharashtra, India. Int J Reprod Contracept Obstet Gynecol 2020;9:34851. 